\title{
Green growth, eco-innovation and sustainable transitions
}

\author{
Francesco Crespi ${ }^{1} \cdot$ Massimiliano Mazzanti $^{2} \cdot$ \\ Shunsuke Managi ${ }^{3,4}$
}

Published online: 25 January 2016

(C) Society for Environmental Economics and Policy Studies and Springer Japan 2016

The special issue revolves around the market, policy and territorial drivers of ecoinnovations, including environmental and technology policies. In more specific terms, it addresses the role of complementarities and interactions between different types of environmental (hereafter, eco) innovations and policy instruments (Borghesi et al. 2015; Managi et al. 2014); it broadens the scope to Regional issues in the adoption of eco-innovations (Cainelli et al. 2015; Managi et al. 2014). It enters the green growth realm by providing insights on the economic and social impacts of eco-innovations (productivity, jobs, skills, Antonioli et al. 2016; Costantini and Mazzanti 2013) and complementary on the environmental impact of eco-innovations.

Eco-innovation studies have expanded and consolidated over the last 15 years, starting from seminal contributions (Rennings 2000; Managi 2015). Those studies have helped linking economics, management and environmental sciences. Over the past years, with mounting emphasis after the 2008-2009 downturn, the role of ecoinnovations (EI) has been included in policy settings that try to reconcile economic

Shunsuke Managi

managi.s@gmail.com

Francesco Crespi

crespi@uniroma3.it

Massimiliano Mazzanti

mzzmsm@unife.it

1 Department of Economics, Roma Tre University, Rome, Italy

2 Department of Economics and Management, University of Ferrara, Ferrara, Italy

3 Urban Institute and Department of Civil Engineering, School of Engineering, Kyushu

University, Fukuoka, Japan

4 QUT Business Shool, Brisbane, Australia 
and environmental performances (EEA 2014). ${ }^{1}$ Green growth paradigms witnesses EI as the leading factor to achieve decoupling. Green economy strategies point to the role of EI as engine of productivity and employment increases. The new European circular economy action plan (EC 2015) focuses on new business models based on product and process EI that should create new markets, namely new sectors, new products, new social willingness to pay for greener and more recyclable goods. EI analyses should highly look at sector heterogeneity because 'each industry is different when it comes to resource use, waste generation and management' (EC 2015).

This innovation-based framework extends the "waste core" of circular economy reasoning to encompass integrated value creation and resource use. Radical innovations, new business models and new consumers' behaviors are needed to improve environmental and economic performances, including new jobs and better use of resources. Regarding global issues such as climate change, EI transfers and diffusion is pivotal to decrease the emission impact of emerging countries while they grow and converge to OECD income levels. EI are embodied in imports and exports so they characterize the possibility to spread greener practices through market and policy levers. Finally, though innovation is cited only in one of the new United Nations' Sustainable Development Goals (SDGs), EI-technological and organizational changes - may be one of the factors that help giving more cohesion to the mere list of SDGs (Kanie and Managi 2014).

Notwithstanding the role of patenting strategies (OECD 2011), the issue contributes to the integrated analyses of invention and innovation. Innovation, namely the adoption and diffusion of EI, is the important issue to look at. It is important as it assumes concrete aspects in different sector and geographical contexts. Its idiosyncratic feature needs a careful and wide investigation at various economic and geographical layers to understand its variety and specificity, in addition to empirical regularities and generalizations. Research needs a varied integration of data: survey data, emission data, balance accounts, micro- and mesodata, official data, to provide rich and informative results to practitioners and policymakers.

The attention of environmental and ecological economics to innovation has often been not a priority, for reasons linked to the paradigms of reference. Innovations treated as a black box by most mainstream theories and scholars, skepticism on the side of ecology. The 'diffusion' of EI concepts and studies contributes to enlarging the scope of mainstream economics and linking economics and management together and then to other disciplines. We might say that EI studies themselves drive the change and support inter-disciplinary research. This issue attempts to propose some new approaches. It tries to fill some gaps in the literature and further contribute to amalgamating perspectives to offer a diversity of analytical and

\footnotetext{
1 The EEA report on the basis of EU data on EI diffusion and economic-environmental indicators analyses, states that "there is room for higher eco-innovation adoption and diffusion in the EU, especially in laggard countries. Higher adoption and diffusion of eco-innovation will further reduce $\mathrm{CO}_{2} / \mathrm{VA}$ indicators across the EU. This is scope for EI oriented policy design in environmental and innovation domains".
} 
empirical approaches. This is needed to capture the complexity of innovation dynamics. We provide below a summary of the contents for the special issue papers.

The first paper included in this special issue analyses the increasing importance of eco-innovations and environmental issues in the post-Kyoto era. Larson and colleagues look at the evolution of green technologies, with special attention devoted to the role played by large multinational firms. They show that the Kyoto Protocol has deeply transformed the framework into which firms operate, inducing a massive trend in favor of the diffusion of energy green technologies. There is evidence that a growing number of firms produce energy green technologies inventions and the overall share of green technologies has increased significantly. However, they find large heterogeneity across countries which tends to be related to national differences in environmental policy. The role of green technologies and public policies in driving a sustainable transition is critically scrutinized by subsequent papers. The effectiveness of green technologies in improving environmental performances and the capacity of public intervention to achieve environmental goals is not that obvious.

In this respect, by exploiting a consolidated empirical framework, the paper by Ding et al., studies whether a relationship exists between green technological change (measured as stock of green patents) and both $\mathrm{CO}_{2}$ emissions and emission efficiency. To investigate this relation, they employed a rich panel covering 95 Italian provinces from 1990 to 2010 . The main results suggest that green technology has not yet played a significant role in promoting environmental protection, although it improved significantly environmental productivity. Interestingly, their result suggests that the identified patterns are not driven by regional differences, and that the main evidence is consistent among different areas of the country.

Braungardt and colleagues provide in their paper complementary analysis on the environmental impact of eco-innovations, by focusing on the case of EU residential electricity use. They claim that even though environmental innovations are generally considered a key element towards a green growth strategy, especially for the case of energy efficiency innovations, the impact on climate can be limited by the so-called rebound effect. More specifically, their study investigates the longterm environmental impact of energy efficiency innovations on the EU-27 residential electricity demand using a bottom-up modeling approach. They showed that assuming a rebound effect of $10 \%$, the diffusion of energy efficiency technologies with current policy levels provides savings of around $140 \mathrm{TWh}$. By contrast, assuming a rebound effect of $40 \%$, the savings are reduced to around 95 TWh until 2030. They conclude that there is a clear case for ambitious policies to support energy efficiency innovations for the residential sector, which ideally should be complemented by measures to limit the rebound effect.

The not obvious relationships between eco-innovation, environmental policies and the effective sustainability performances are further explored by Range and Sandberg who look into climate gas emission and the shift to non-fossil energy in Sweden. Their results obtained through an analysis of energy usages among Swedish industrial organizations in the period 2003-2011 is following. It shows that neither energy consumption, economic indicators of the organizations or the education levels in general play important roles for why these organizations 
innovate in the direction to or from the use of non-fossil sources. The observed shift to non-fossil use to a large degree is a question of using wood fuels instead of fossil oil. This shift, however, does not affect $\mathrm{CO}_{2}$ emissions and is not of high-tech or technological character, or effects of the level of education among employees.

The paper by Fujii and colleagues analyses whether the financial crisis has had an impact in this context, by looking at the dynamics of environmental and technical efficiencies of the Japanese manufacturing industry. They find that while the crisis had a negative impact on technical efficiency, it did not affect environmental efficiency. Moreover, they show that capital intensity does not necessarily affect environmental efficiency. Both technical and environmental efficiencies are estimated using a Bayesian stochastic frontier approach and then conducted a second-stage Tobit analysis to assess the impact of the financial crisis across several manufacturing sectors.

Their evidence suggests that the impact of the crisis is sector specific. Hence, they claim that policy makers should consider the industrial characteristics of production when suggesting the economic recovery policy for manufacturing firms.

The policy implications deriving from this first set of paper that evidenced the problematic links between the evolution of green technologies and the achievement of environmental goals by policy makers are developed in the final two papers of this special issue. While the analysis provided by Crespi offers a general assessment of the difficulties in implementing an effective policy design due to policy complexity reasons, the paper by Friesenbichler specifically addresses the trade-offs in energy policy objectives that pose frictions to the establishment of a new technology base.

In particular Crespi in his contribution, by acknowledging the inherent complexity of system dynamics, argues that the green transformation of the economies can be conceptualized as the outcome of an emergent system property and highlights the difficulties related to the development of an integrated framework of policy instruments that accounts for their mutual interaction. In this respect, the paper elaborates on the concept of Green Transition System, suggesting the importance of activating learning and adaptive mechanisms involving private agents, stakeholders, policy makers and scholars interested and involved in the transition process.

On the other hand, Friesenbichler investigates how institutions in an evolving electricity system can be designed to best achieve policy targets that are partly conflicting. He develops a case study of the electricity sectors in Germany, Spain, and Denmark, considering three policy fields. His results indicate that a lack of a clear hierarchy of objectives is reflected in current policy debates. However, institutions that impose a hierarchy of policy objectives and prioritizes security of supply over sustainability and competitiveness may solve issues arising from the displacement effect and achieve superior policy effectiveness. Finally, Fujii and Managi note the importance of data such as patent data disclosure. They propose a new corporate financial and environmental dataset called the World Resource Table. 


\section{References}

Antonioli D, Borghesi S, Mazzanti M (2016) Are regional systems greening the economy? Local spillovers, green innovations and firm's economic performances. Econ Innov New Technol. doi:10. 1080/10438599.2015.1127557

Borghesi S, Crespi F, D’Amato A, Mazzanti M, Silvestri F (2015) Carbon abatement, sector heterogeneity and policy responses: evidence on induced eco innovations in the EU, Environmental Science and Policy, December

Cainelli G, D’Amato A, Mazzanti M (2015) Adoption of waste-reducing technology in manufacturing: regional factors and policy issues. Resour Energy Econ 41:185-201

Costantini V, Mazzanti M (2013) The dynamics of economic and environmental systems. Innovation, policy and competitiveness. Springer, Berlin

EC (2015) Communication from the Commission to the European Parliament, the Council, The European Economic and Social Committee and the Committee of the Regions, Closing the loop-an EU action plan for the circular economy, COM (2015) 614/2

EEA (2014) Resource-efficient green economy and EU policies, 2-2014 EEA Report

Kanie N, Managi S (2014) Stimulating 2015 climate deal: governance of low carbon technology transfer. Environ Econ Policy Stud 16(2):111-113

Managi S (ed) (2015) The Routledge handbook of environmental economics in Asia. Routledge, New York

Managi S, Hibiki A, Shimane T (2014) Efficiency or technology adoption: a case study in wastetreatment technology. Resour Energy Econ 36(2):586-600

OECD (2011) Invention and transfer of environmental technologies. OECD, Paris

Rennings K (2000) Redefining innovation-eco-innovation research and the contribution from ecological economics. Ecol Econ 32:319-332 